\title{
Article
}

\section{Vocal cord palsy as a sequela of paediatric cardiac surgery - a review}

Sinha, Aditi, Geragotellis, Alexander, Singh, Guntaj Kaur, Verma, Devika, Ansari, Daniyal Matin, Tarmahomed, Abdullah, Whitehall, Emma, Lowe, Natalie, Ashry, Amer and Harky, Amer

Available at http://clok.uclan.ac.uk/37434/

Sinha, Aditi, Geragotellis, Alexander, Singh, Guntaj Kaur, Verma, Devika, Ansari, Daniyal Matin, Tarmahomed, Abdullah, Whitehall, Emma, Lowe, Natalie, Ashry, Amer et al (2021) Vocal cord palsy as a sequela of paediatric cardiac surgery - a review. Cardiology in the Young . ISSN 1047-9511

It is advisable to refer to the publisher's version if you intend to cite from the work. http://dx.doi.org/10.1017/S1047951121001165

For more information about UCLan's research in this area go to http://www.uclan.ac.uk/researchgroups/ and search for < name of research Group>.

For information about Research generally at UCLan please go to http://www.uclan.ac.uk/research/

All outputs in CLoK are protected by Intellectual Property Rights law, including Copyright law. Copyright, IPR and Moral Rights for the works on this site are retained by the individual authors and/or other copyright owners. Terms and conditions for use of this material are defined in the policies page.

\section{CLoK}

Central Lancashire online Knowledge www.clok.uclan.ac.uk

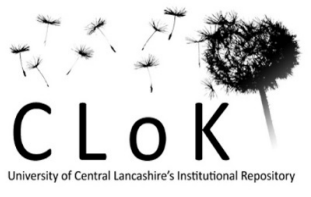




\section{Vocal cord palsy as a sequela of paediatric cardiac surgery - a review}

\begin{tabular}{|c|c|}
\hline Journal: & Cardiology in the Young \\
\hline Manuscript ID & CTY-21-Feb-121.R1 \\
\hline Manuscript Type: & Original Article \\
\hline $\begin{array}{r}\text { Date Submitted by the } \\
\text { Author: }\end{array}$ & 02-Mar-2021 \\
\hline Complete List of Authors: & $\begin{array}{l}\text { Sinha, Aditi; St George's Healthcare NHS Trust } \\
\text { Geragotellis, Alexander; University of Cape Town } \\
\text { Singh, Guntaj ; University of Central Lancashire } \\
\text { Verma, Devika; University of Central Lancashire } \\
\text { Ansari, Daniyal Matin; St George's Healthcare NHS Trust } \\
\text { Tarmahomed, Abdullah; Alder Hey Children's NHS Foundation Trust } \\
\text { Whitehall, Emma; Alder Hey Children's NHS Foundation Trust } \\
\text { Lowe, Natalie; Alder Hey Children's NHS Foundation Trust } \\
\text { Ashry, Amr; Alder Hey Children's NHS Foundation Trust; Assiut } \\
\text { University } \\
\text { Harky, Amer; Liverpool Heart and Chest Hospital NHS Foundation Trust, } \\
\text { Department of Cardiothoracic Surgery }\end{array}$ \\
\hline Keywords: & Vocal cord, Cardiac, Surgery \\
\hline Manuscript Category: & Surgery \\
\hline \multicolumn{2}{|l|}{ Subspeciality Collections: } \\
\hline \multicolumn{2}{|l|}{$\begin{array}{r}\text { Diagnostic and Procedural } \\
\text { Collections: }\end{array}$} \\
\hline Abstract: & $\begin{array}{l}\text { Background: Vocal cord palsy (VCP) is a recognised complication of } \\
\text { cardiac surgery in the paediatric population and can lead to debilitating } \\
\text { complications. Whilst there is an abundance of literature highlighting the } \\
\text { presence of this complication, there is a scarcity of research focusing on } \\
\text { the pathophysiology, presentation, diagnosis, and treatment options } \\
\text { available for children affected by VCP. } \\
\text { Materials and methods: Electronic searches were conducted using the } \\
\text { search terms: "Vocal Cord Palsy", "VCP", "Vocal Cord Injury", "Paediatric } \\
\text { Heart Surgery", "Congenital Heart Surgery", "Pediatric Heart Surgery", } \\
\text { "Vocal Fold Movement Impairment", "VFMI", "Vocal Fold Palsy", "PDA } \\
\text { Ligation". The inclusion criteria were any articles discussing the } \\
\text { outcomes of VCP following paediatric cardiac surgery. } \\
\text { Results: The available literature surrounding the topic have been } \\
\text { summarized within their appropriate sections. The two main populations } \\
\text { affected by VCP are paediatric patients undergoing aortic arch surgery or } \\
\text { those undergoing PDA ligation. There is paucity of prospective follow-up } \\
\text { studies; it is therefore difficult to reliably assess the current approaches } \\
\text { and the long-term implications of management options. } \\
\text { Conclusion: VCP can be a devastating complication following cardiac } \\
\text { surgery, which if left untreated, could potentially result in debilitation of } \\
\text { quality of life and in severe circumstances could even lead to death. } \\
\text { Currently, there is not enough high-quality evidence in the literature to }\end{array}$ \\
\hline
\end{tabular}


aid recognition, diagnosis, and management leaving clinicians to extrapolate evidence from adult studies to make clinical judgements.

Future research with a focus on the paediatric perspective is necessary in providing evidence for good standards of care.

\section{SCHOLARONE ${ }^{m}$ \\ Manuscripts}




\title{
Vocal cord palsy as a sequela of paediatric cardiac surgery - a review
}

\author{
Running title: Nerve injury
}

Aditi Sinha BSc${ }^{1}$, Alexander Geragotellis², Guntaj Kaur Singh BSc ${ }^{3}$, Devika Verma ${ }^{3}$, Daniyal Matin Ansari ${ }^{1}$, Abdullah Tarmahomed MRCPCH ${ }^{4}$, Emma Whitehall MRCS (ENT) ${ }^{5}$, Natalie Lowe MRCS (ENT) ${ }^{5}$, Amr Ashry MRCS7,8, Amer Harky MSc MRCS6,8.

1. St George's University of London, Tooting, London, SW17 ORE

2. Faculty of Health Sciences, University of Cape Town, Anzio Road, Observatory, Cape Town, South Africa

3. University of Central Lancashire, Lancashire, Preston, PR1 2HE, United Kingdom

4. Department of Paediatric Cardiology, Alder Hey Children's Hospital, Liverpool, UK

5. Department of ENT, Alder Hey Children Hospital, Liverpool, UK

6. Department of Congenital Cardiac Surgery, Alder Hey Children Hospital, Liverpool, UK

7. School of Medicine, University of Assiut, Assiut, Egypt

8. Department of Cardiothoracic Surgery, Liverpool Heart and Chest Hospital, Liverpool, L14 3PE, United Kingdom

\section{Corresponding Author:}

Amer Harky

MBChB, MSc, MRCS

Liverpool Heart and Chest Hospital

Thomas Drive, L14 3PE, United Kingdom

E-mail: aaharky@gmail.com

Tel: +44-151-600-1616

\section{Keywords:}

Vocal Cord Palsy, Vocal Cord Injury, Paediatric Heart Surgery, Congenital Heart Surgery, Recovery, Outcomes

\section{Declarations:}

Nothing to declare

\section{Funding:}

No funding obtained 


\section{Abstract:}

Background: Vocal cord palsy (VCP) is one of the recognised complications of complex cardiac surgery in the paediatric population. Whilst there is an abundance of literature highlighting the presence of this complication, there is a scarcity of research focusing on the pathophysiology, presentation, diagnosis, and treatment options available for children affected by VCP.

Materials and methods: Electronic searches were conducted using the search terms: "Vocal Cord Palsy", "VCP", "Vocal Cord Injury", "Paediatric Heart Surgery", "Congenital Heart Surgery", "Pediatric Heart Surgery", "Vocal Fold Movement Impairment", "VFMI", "Vocal Fold Palsy", "PDA Ligation". The inclusion criteria were any articles discussing the outcomes of VCP following paediatric cardiac surgery.

Results: The two main populations affected by VCP are paediatric patients undergoing aortic arch surgery or those undergoing PDA ligation. There is paucity of prospective follow-up studies; it is therefore difficult to reliably assess the current approaches and the long-term implications of management options.

Conclusion: VCP can be a devastating complication following cardiac surgery, which if left untreated, could potentially result in debilitation of quality of life and in severe circumstances could even lead to death. Currently, there is not enough high-quality evidence in the literature to aid recognition, diagnosis, and management leaving clinicians to extrapolate evidence from adult studies to make clinical judgements. Future research with a focus on the paediatric perspective is necessary in providing evidence for good standards of care. 


\section{Introduction:}

Congenital heart disease afflicts approximately $0.8-1.2 \%$ of live births worldwide [1-3]. A third of the defects can be expected to be severe and present as candidates for cardiac surgery $[4,5]$. Vocal cord palsy (VCP) is a recognised and important complication in children which can follow congenital cardiac surgery. VCP may result when either one or both of the recurrent laryngeal nerves (RLNs) are damaged; these children may present with speech, feeding, and respiratory impediments which are exaggerated in bilateral VCP (BVCP) [6].

latrogenic injury to the nerve fibres during an invasive surgical intervention may result in the paralysis of unilateral or bilateral vocal cords [7]. Daya et al. described that left-sided VCP, was more common than bilateral VCP following paediatric cardiac surgery [6].

The risk of VCP occurring is contingent on patient and surgical aspects. Patient-related factors include female gender, prematurity, and low birth weight $[8,9]$. Additionally, aortic arch manipulations and PDA ligations pose the most significant procedural risks of VCP [10]. Anticipating these factors better prepares the clinician for multidisciplinary collaboration especially with otolaryngology and anaesthesiology for the management of emergency airway obstruction.

It is particularly important to consider the variable complications, long-term outcomes, and quality of life for the VCP patient. There will invariably be differences in the extent to which the nerves and vocal cords are affected between patients, and by extension, the degree to which phonatory and respiratory functions are affected. In an acute setting, airway obstruction is a life-threatening complication of VCP and if not treated can lead to aspiration, respiratory distress, and even death [10]. In the longer-term, a developing child's ability to engage in conversation or eat without the need of feeding tubes can all be compromised. This can also be detrimental to both the child and their family's quality of life [11]. Appropriate knowledge on VCP is important as it can guide the diagnosis and management. Additionally, many areas of the multidisciplinary team such as cardiology, otolaryngology, anaesthesia, and speech-language therapy can benefit from this highquality evidence. Additionally, there are very few long-term follow-up studies that have assessed the quality of life and long-term impacts of children affected, making it difficult to dictate necessary clinical interventions following discharge.

The aim of this review is to summarise and evaluate the available evidence surrounding VCP following cardiac surgery in the paediatric population, with a broader focus on management strategies and the impact on quality of life for these patients.

\section{Clinical assessment of patients with VCP:}

The clinical presentation of a child with VCP can be split broadly into features affecting phonation and features affecting respiration. The most common, and sometimes the only feature of VCP, is the presence of stridor. Bilateral vocal cord palsy (BVCP) has been reported to have a higher incidence and more severe presentation of stridor compared to unilateral VCP (UVCP). Other symptoms include a weak cry, dysphagia, and potential 
aspiration. Intercurrent cardiac and neurological disorders can also complicate the clinical picture and cause or contribute to respiratory distress [6].

While the occurrence of VCP following cardiac surgery is rare, it is important to note that this is heavily reliant on the child's clinical examination. As many patients may be asymptomatic or only present with subtle clinical signs after a certain period of time, they may have not been adequately investigated initially [10]. Investigations are either invasive or non-invasive, and each carry associated advantages and disadvantages to both the child and clinician.

\section{1: Non-invasive methods}

A non-invasive method that can be undertaken at the bedside is the use of ultrasound to study vocal cord mobility. Shaath et al [12] conducted a study with 10 children who had undergone heart surgery and used ultrasound to assess the movements of the vocal cords. They found it was successful in recognising when VCP was not present. However, it was not as successful in diagnosing VCP as there could be some movement of the vocal cords despite being paralysed [12]. Ultrasound is normally used as an adjunct to endoscopy rather than as an alternative.

\section{2: Invasive methods}

Laryngoscopy is an invasive intervention that is used for vocal cord visualization. Literature suggests that fibreoptic flexible laryngoscopy (FL) should be utilised when investigating VCP and may be the only diagnostic option necessary as it allows clear visualisation of the vocal cord dynamics and the patency of the airway [13].

Direct rigid laryngoscopy can be conducted under general anaesthesia. A competitive advantage over $\mathrm{FL}$ is that the arytenoids can be palpated to exclude cricoarytenoid joint fixation, which is another differential of VCP [6]. However, the palpation should be done cautiously to avoid iatrogenic injury which could lead to prolonged intubation. The use of either FL or rigid laryngoscopy should be carried out regularly to assess the status of the vocal cords and to monitor after treatment for improvement [14].

Laryngeal electromyography (LEMG) can also be utilised to assess recurrent laryngeal nerve function. Monitoring electrodes are attached to the thyroarytenoid muscles intraoperatively to look at the extent of immobility. A retrospective study by Scott et al. [15] found that in $50 \%$ of patients, the results from LEMG resulted in a change in management for the patient. Additionally, Maturo et al. [16] built on Scott et al.'s [15] work and used LEMG as a method to predict if recurrent laryngeal nerve function would return. In children who had undergone PDA ligation, they found that the absence of action potentials by 6 months meant it was unlikely that the VCP would resolve [16].

Having expressed that routine diagnosis ought to replace symptomatic diagnosis, the utility of diagnostic methods must be considered. Whilst FL is the preferred choice, it can be challenging to perform in young children. Nonetheless, it performs better than direct laryngoscopy - which requires a greater level of user expertise and in smaller neonates, it may require general anaesthesia. Non-invasive methods such as ultrasound are also very user-dependent and may not be opted for in severe or life-threatening presentations of 
VCP. The diagnostic method is crucial in the assessment and treatment of VCP; not only does it dictate the next step but can also be used to predict the outcome for the child and hence the quality of life. Regular use of $\mathrm{FL}$ is recommended to assess the patency of the airway and vocal cord status.

\section{Management:}

Management options for VCP can be split into two options: medical and surgical. Following diagnosis, the clinician will be able to evaluate the need, type, and urgency of treatment.

\section{1: Medical Management}

Before deciding the modality of treatment, the child can be observed through clinical observation and serially measuring oxygen saturations to check for respiratory distress [6]. If the child shows signs of airway compromise, more urgent intervention is required. Spontaneous recovery is an option for VCP in stable children where a 'wait and watch' method is adopted. The mechanism of this process is not well understood however, in UVCP it is hypothesised that the healthy vocal cord can compensate for the other until neurological regeneration occurs [17]. During this time, the use of a nasogastric tube is common until the child is able to adequately cough and swallow [18].

Another option is speech therapy which has been found to be successful, particularly in older children. While there is a lack of reported evidence for VCP following cardiac surgery, $84 \%$ of patients with neurological malignancies found improvement in both speech and swallowing function. Further clinical trials are necessary to ascertain if this remains true for children with VCP following cardiac surgery.

Steroid therapy is favoured due to its likelihood of helping to reduce post-operative voice changes by preventing surgery-related complications such as oedema, which are linked to voice change [19]. Aside from their analgesic, prophylactic and antiemetic properties, steroids are also able to promote post-paresis nerve function recovery [20] and are used as part of the treatment of hoarseness [21]. A single-dose of intraoperative steroids can reduce the duration of temporary RLN palsy; however, it does not reduce the rate of RLN palsy [20] nor does it have a beneficial effect on voice-related quality of life [19].

\section{2: Surgical Management}

Surgical management is undertaken after the recommended 8-12 months period of observation; unless the child is initially unstable and requires early surgical intervention to protect the airway. Findings from Jabbour et al. [22] and Misono et al. [20] indicate that between $20-40 \%$ of children remain symptomatic with UVCP and emerge as candidates for surgical intervention. The main surgical interventions for UVCP are medialisation (injection laryngoplasty or type 1 thyroplasty) and non-selective recurrent laryngeal innervation and as shown in Table 1, each procedure carries its own set of advantages and disadvantages [21]. The most popular BVCP interventions are tracheostomy and iterations of posterior cordotomy [23].

\subsection{1: Surgical management for UVCP}




\section{Injection Laryngoplasty}

This involves injecting a synthetic material into the paralysed cord to medialise it [21]. The aim is to allow phonation and prevent aspiration, as a temporizing intervention either to mitigate symptoms or in anticipation of spontaneous reinnervation [24]; it is also used in the immediate postoperative period prior to non-selective laryngeal nerve innervation [21]. It has great utility in treatment plans aiming to initiate and/or advance an oral diet in paediatric patients with surgically induced VCP, especially if conducted within 6 months of the surgical injury [25]. There are a variety of materials available with variable immunogenicity such as Teflon, hyaluronic acid, collagen [21], and carboxymethylcellulose, which despite lasting between 1-2 months, is a strong material option as it has a safe biological profile with few reported complications and good outcomes in voice improvement [21].

\section{Type 1 Thyroplasty}

Type 1 Thyroplasty is a technically demanding and invasive procedure involving the insertion of synthetic implants through a window fashioned in the thyroid cartilage. The materials used are either Silastic, cartilage, or Gore-Tex [20, 26], for which there are less reported immunogenic effects than for injection laryngoplasty materials [16]. Butskiy et al. [27] reported $88 \%(n=8)$ improvement or recovery from aspiration in children and this finding could be the substrate of further clinical study amongst larger cohorts. Revisions are necessary, however, in paediatric patients to accommodate the growing and developing laryngeal anatomy [21]. The anticipated amount and frequency of these revisions is difficult to deduce from the scarcity of available long-term follow-up data [27]. In any case, delayed access is understood to cause increasingly greater technical challenges, especially if conducted post-puberty [28]. Owing to its failure to correct persistent phonatory gaps [21], Isshiki et al. [29] first described arytenoid adduction as a relatively simple yet critical adjunct to Type 1 Thyroplasty, despite its leading to longer procedural times and being technically challenging [30].

\section{Reinnervation}

Non-selective recurrent laryngeal reinnervation (NSLR) of the abductor and adductor intrinsic muscles of the larynx is achieved by anastomosing the RLN to itself or an adjacent motor nerve [23]. In comparison to static medialisation thyroplasty, NSLR confers a higher voice quality due to better vibrational capacity of the vocal cords [31, 32] with more longterm stability owing to preserved laryngeal muscle bulk and tone [31]. It confers a significantly reduced risk of aspiration in children due to the improved glottic closure patterns [24]. It has been recommended that the optimal time for NSLRI is after 3 years of age [21]. Although general anaesthesia [33] obviates the need for intraoperative patient cooperativity, there are concerns related to the neurocognitive harm caused by prolonged anaesthetic time [34].

The independence from synthetic materials allows laryngeal development and removes the necessity for revision surgeries that are associated with thyroplasty. The procedure is understood to be safe without a significant risk of airway or wound complications [33, 35], but a consultation with a paediatric cardiologist would be useful in any case when assessing operative risk. Unlike the medialisation techniques, the improvement seen with UVCP is not immediate. Findings from Smith et al. [33] - which shows consistency with other studies 
from a systematic review of laryngeal reinnervation techniques [35] - suggest that a positive improvement from reinnervation can be expected after a minimum of 6 months with stable results by 12 months. Having already undergone previous cardiac surgery, patients (and/or their parents) may show resistance to the prospect of further surgery due to additional scarring [24] and so ought to be counselled appropriately on the implications and long-term benefits. Ongkasuwan et al [36] suggests that NSLR procedures should be performed as early as possible to optimise outcomes but also noted that favourable outcomes could still be achieved two decades after the onset of childhood neuronal VCP. They also speculate that preoperative LEMG may have utility in predicting voice outcomes following NSLR but that further data is required [36].

\subsection{2: Surgical management for BVCP}

\section{Iterations of posterior cordotomy}

This is an irreversible procedure that improves the laryngeal airway by removing a posterior section of the vocal fold, while potentially sacrificing voice and/or swallowing ability [23]. Despite modification by otolaryngologists in recent years to mitigate these compromises, the treatment approach remains suboptimal [37].

\section{Tracheostomy}

A tracheostomy involves either a temporary or permanent opening of the trachea. This gives relief of airway obstruction and protection from aspiration but does not improve phonation (and will remove any ability to phonate unless fenestrated) [38]. Despite a tracheostomy improving the airway [23], findings by Westwood et al. [39] substantiate that there is an inherent compromise on quality of life for both the patient and their caregivers and recommend psychosocial support for families. The main problem is the stoma that requires continual care [40] and so research of less-invasive techniques is ongoing [38].

\section{Selective reinnervation}

In contrast to NSLRI, selective recurrent laryngeal innervation of the posterior cricoarytenoid muscles - involves specifically reinnervating distal abductor branches of the RLN [23]. Crumley [41] was instrumental in defining the phrenic nerve as a donor target for the abductor muscle bellies. A case series by Lee et al. [42] enforced a belief of the technique's safety and appropriate use in children as young as 2 years old. Evidence remains largely limited to adult patients however and further studies with larger sample sizes are warranted for this promising technique.

\section{Arytenoidectomy}

This is the irreversible surgical removal of the arytenoid cartilage to enlarge the airway [30]. Advances in arytenoidectomy procedures started with the use of endoscopic lasers, which resulted in increased precision and decreased oedema post-surgery, and most importantly, did not require tracheostomy to be performed [38]. However, surrounding tissues can be damaged by the heat from the lasers, leading to increased susceptibility to granuloma and scar formation, and thus resulting in more revision surgeries as the airways will inevitably re-narrow [44]. Arytenoidectomy can be combined with arytenoid cordectomy or used alone, yet both procedures can adversely affect voice quality [37]. 


\section{Laterofixation (Suture lateralisation/laterofixation)}

Laterofixation of the vocal cord and/or arytenoid cartilage is indicated in BVCP patients as an alternative to tracheostomy or as a temporising measure when the recovery of laryngeal function is expected [44]. It reversibly enlarges the airway without damaging phonatory tissues so that voice can be later be restored and it can be performed independently or concurrently to endoscopic procedures [37]. Good success rates have been reported in paediatric cohorts [44] with superior performances in aerodynamic measures when compared to irreversible static procedures (e.g., cordotomy and arytenoidectomy); nonetheless, complications including aspiration, hoarseness, and need for adjustments should be anticipated [37].

\section{Laryngeal pacing (Functional electrical stimulation)}

Laryngeal pacing is an upcoming surgical option that has the potential to confer high-quality ventilatory improvement in the absence of swallowing and phonatory compromise [37]. As demonstrated by Mueller [45], the laryngeal pacing system involves electrode stimulation of the posterior cricoarytenoid (PCA) muscle(s) with the implant being situated in a subcutaneous pocket of the sternum. Candidates with aberrant RLN reinnervation will optimise the utility of this procedure [45]. Future research ought to address the absence of paediatric data for this technique [38]. The actual procedure itself is complicated and also proves expensive as the device needs replacement at least every 10 years [46].

\section{Botulinum injection}

The toxin botulinum is also used in the treatment of BVCP, especially in patients with laryngeal synkinesis, which is the involuntary movement of muscles following voluntary movement in one muscle. It promotes ventilation by causing flaccid paralysis in adductor muscles through inhibiting acetylcholine from being released from axon terminals [37]. Once adductor inspiratory motor neurons and muscles are blocked, abductor inspiratory motor neurons are able to produce a glottal opening, thereby enabling ventilation. Unlike cordotomy and arytenoidectomy, this treatment option has little to no effect on the voice. However, it is only a temporary fix as repeated injections are required every 3 months [37].

\section{3: Future management options:}

Further research could offer enhanced detail into our understanding of VCP and allow better diagnosis and treatment. Alternative therapies that promise regeneration of the laryngeal nerves and muscle trophism is gene therapy [37]. Gene therapy offers exciting prospects; whilst untested in the paediatric community, gene transduction is in pre-clinical trials for adult patients. Vectors can be delivered to certain points of the body such as the nervous system, musculature, or mucosa around the larynx. This could provide protection to the neurons, regeneration of the axons, and also prevention of muscle degeneration [47]. However, while gene therapy is under consideration for treatment of BVCP caused by neurodegenerative conditions, it does not prevent synkinesis [37]. Gene therapies also pose a risk of neuronal damage via the delivery of viral vectors into the CNS [38]. Gene therapy is still in the experimental stages, and more research is needed to test the effectiveness of 
neuronal regeneration and to find solutions to their adverse effects, before it can be considered as treatments for iatrogenic BVCP, especially in the paediatric population.

\section{Outcomes:}

The outcome of patients with VCP post-cardiac surgery varies with respect to a number of factors such as site (either unilateral or bilateral), gestational age, and surgical procedure. The complications following VCP can either be transient or permanent and vary widely in severity [14].

\subsection{Recovery:}

A recent systematic review by Engeseth et al. [48] reported low left VCP recovery rates (0$33 \%$ ) from a range of PDA ligation studies (17 retrospective; 4 prospective) which exposes infants to life-long complications. Table 2 supports that the recovery of vocal fold function following congenital cardiac surgery is subject to substantial variation based on surgical procedure and gestational age. The highest rate of recovery is seen with aortic arch repair, specifically the Non-Norwood procedures with $86 \%$, while the lowest rate of recovery is seen in PDA ligation with $0 \%[49,50]$. Supportive care should be implemented during the postoperative period to aid the recovery of VCP [10]. It is also important to observe that a variation exists in the length of follow-up periods for VCP recovery across different studies which range between 3-16.4 months in Table 2. Many studies have relatively short-follow up periods which may prompt underestimated VCP recovery rates - there could be under detected greater rates of resolution within asymptomatic cohorts [50]. Additionally, without conducting pre- and postoperative $\mathrm{FL}$, there are inconsistencies in the evaluation of vocal cord motion before and after therapeutic intervention which challenges the comparability of studies.

Truong et al. [50] observed that premature infants, especially neonates ( $\leq 28$ weeks gestational age), had lower rates of recovery of vocal cord function in comparison to infants born at term across a variety of cardiac surgeries. Evidence from Zbar et. al [52] suggests that infants of greater prematurity and lower birth weight are more likely to develop left VCP during PDA ligations. Birth weight also appears to play a focal role in the incidence of left sided VCP following PDA ligation; a greater incidence was found in infants with a lower birth weight ( 5 of $22 ; 22.7 \%$ ), compared to the incidence for heavier babies ( 1 of $46 ; 2.2 \%$ ) [52]. Infants that weigh $\leq 1 \mathrm{~kg}$ at birth are defined as extremely low birth weight (ELBW) and it is preferential to use clips during PDA ligation in this population to lessen the extent of dissection and mitigate the risk of injury to the great vessels. However, using clips is associated with higher rates of VCP; it can result in RLN injury due to the close proximity of the RLN to the ligation site [52]. Meticulous monitoring of ELBW infants undergoing PDA ligation is imperative - Benjamin et al. [14] found an increased likelihood of bronchopulmonary dysplasia, reactive airway disease or insertion of a gastrostomy tube in this cohort.

\subsection{Adverse Outcomes}

Engeseth et. al [48] highlighted that left VCP is associated with a range of adverse outcomes among infants. There is a wide range of adverse outcomes spanning respiratory outcomes and comorbidities such as bronchopulmonary dysplasia, laryngeal outcomes (dysphonia, laryngomalacia, subglottic stenosis), feeding outcomes (gastrostomy, tube feeding) and 
other outcomes (hospital stay, readmission rate) [48]. For example, a retrospective study by Nichols et al. [53] reviewed the functional outcomes with vocal fold immobility in patients after isolated PDA ligation. The presence of symptoms such as dysphonia (48\%), dysphagia (27\%), enteral tube feeds (24\%) and respiratory symptoms i.e., stridor, increased work of breathing (11\%) were observed in this patient cohort with a median follow-up of 3 years. This paper concluded that there is an association between the severity of clinical dysfunction at presentation and clinical outcomes [53].

Karas et al. [11] advocate that parents and primary care providers should be counselled that there is a $46 \%$ probability of children requiring a surgical feeding tube after sustaining VCP post-cardiac surgery. They also discuss, in addition to others $[54,55,56]$ that infants undergoing correction of larger structural defects with longer operative times and more extensive dissection near the recurrent laryngeal nerve have shown greater rates of intubations which is speculated to be due to lesser contralateral vocal fold compensation [17].

\section{Quality of life (QoL):}

Considering the patient's QoL is crucial to better understand the consequences of VCP and its treatment [57]. Despite a catalogue of available instruments for its assessment, QoL remains a complex concept that is defined and interpreted in a variety of ways across and within various medical disciplines globally [57]. The utility of the Paediatric Voice-Related Quality of Life ( $p V R Q O L)$ survey was validated in a study by Boseley et al. [58] as a more comprehensive instrument than the Paediatric Voice Outcomes Survey ( $p V O S)$. Whilst pVRQOL results report social-emotional and physical-functional effects, pVOS is less sensitive and only documents global preoperative and postoperative changes [58]. Walz et al. [59] found that the pVRQOL score in premature paediatric patients with a history of cardiac surgery is significantly lower than those without a history of cardiac surgery. There was no explanation given as to whether the reason for a decrease in the pVRQOL score was due to recurrent laryngeal nerve injury. To our knowledge, there is no literature that directly associates QoL, recurrent laryngeal nerve injury (and hence VCP), and paediatric cardiac surgery. All references to QoL are thus noted to be anecdotal in nature.

Post-cardiac surgery, it is clear that children are at significant risk of aspiration (which could lead to pulmonary injury) and dysphagia due to vocal fold dysfunction [54, 60, 52]. Reports documenting post-operative occurrences are abundant yet there is a scarcity of data describing long-term follow-up [51, 48,61]. The effects of dysphonia can be devastating for the social development of a child resulting in shyness, withdrawal at school, and general difficulty in engaging with others [8].

Rodney et al. [8] - whose comparative analysis showed non-significant differences across the majority of postoperative variables between VCP and non-VCP neonates except for aspiration - suggested that the QoL is predominantly impacted when there is insufficient self-resolution of the VCP or when a diagnosis is missed. Follow-up with an otolaryngologist is therefore of major importance yet may be overlooked due to lack of fail-safe institutional measures to ensure that every VCP patient receives a follow-up appointment. This could also be amplified further by insufficient foresight from the cardiac team to refer to otolaryngology when noting VCP during their designated follow-up [8]. Retrospective 
findings from Jabbour et al. [22] revealed only a $24 \%$ resolution rate $(n=278)$ in their paediatric cardiac surgery population - which is similar to the $35 \%(n=80)$ reported by Truong et al. [51]. They also proposed a regimented follow-up plan that could be adopted for all paediatric VCP patients as shown in figure 1 [22].

Importantly, Rodney et al. [8] highlight that through effective counselling, physicians can fully prepare parents of aortic arch reconstruction patients to both manage aspiration with modified feeding and anticipate potential sequelae. This can also subdue concerns of aspiration-related pneumonia, gastrostomy, and tracheostomy (for BVCP) due to their relative rarity [8]. Resiliency of the neonatal lungs was cited as a potential explanation for the evasion of respiratory sequelae [8].

As described by Dewan et al. [18], in addition to modified feeding, presentations of aspiration and dysphagia may require further dietary augmentation through delivery via gastrostomy or nasogastric tube. They found that VCP neonates are more likely to experience an abnormal cough and gag-reflex and require an increased length of hospitalisation due to the tube feeding [18]. Supportive findings by Sachdeva et al. [55] indicated that $87 \%(n=38)$ of VCP paediatric in their cohort were intolerant of full oral feeds at discharge and requiring modification to their nutritional intake, potentially with a modified delivery method. Recent findings from Richter et al. [61] suggest that there is an expected time to regular oral feeding of less than 2 years irrespective of the infants' VCP status and genetic comorbidities. Despite the good prognosis, parents of VCP infants should be informed of modified diets at discharge and that there is a greater long-term risk for inpatient hospitalisation due to feeding difficulties and poor weight gain [61].

Sequelae of VCP such as prolonged tube feeding, and dysphonia could significantly impact both the parent and the child as well as their relationship. More quality-of-life evaluations could be conducted in the future pertaining to the children and their families; voice-related QoL, for instance, is a metric that could be better represented. Whilst Walz. et al. [59] discussed voice-related QoL for a premature paediatric cohort, there could be further pVOS/pVRQOL short-term and long-term studies in a broader-aged paediatric cardiac surgery population for patients experiencing VCP. For older paediatric patients, retrospective QoL studies could be conducted to quantify the extent to which the condition affected their lives prior to intervention and be the substrate for additional future interdisciplinary interventions to better support this group.

\section{Summary:}

Advances in paediatric cardiac surgery and medical care have caused a paradigm shift in patient care and survival. Patients with prematurity and complex congenital cardiac diseases are increasingly surviving their initial challenges and leading productive lives. The possibility of an increased prevalence of VCP in children is therefore likely, particularly with emerging undetected VCP cases. Variation in the reported causes of VCP is likely institution-specific and attributable to the paediatric cardiac surgery activity (figure 2) [6] - it is therefore difficult to ascertain fully representative statistics in regions where healthcare infrastructure remains underdeveloped. 
Patients at greater risk of VCP are female, premature and low-birth weight undergoing either or both PDA ligation or aortic arch interventions. Avoiding the serious complications of aspiration and dysphagia are at the forefront of management decisions for the childsurgical feeding tubes are therefore common [11]. Clinicians should be prepared to counsel either or both patients and their families on the QoL implications, which remains an area that requires further study. Certain events, such as aspiration-related pneumonia and gastrostomy, could be informed as rarities for aortic-reconstruction patients [8]. On the contrary, clinicians should expect respiratory complications and enteral feeding for surgical PDA ligation patients [14].

Prospective multi-centre cohort studies are warranted in future and should aim to identify further VCP risk factors and better assess presentations such as voice and swallowing. Longer-term stricter institutional follow-ups will lend to enhanced understanding of true recovery rates. Pre- and post- operative FL should be conducted universally to prevent VCP underestimation in asymptomatic patients and promote early detection. Nonetheless, primary care providers should remain cautious as to not to overlook insidious cases of VCP which many present with similar symptoms to asthma in older children [62].

\section{Conclusion:}

Cardiac surgery remains the leading cause of iatrogenic VCP in the paediatric population. Early recognition and management of VCP following cardiac surgery is vital to improve recovery and reduce morbidity and mortality. This is particularly important given that VCP can present insidiously or be mistaken for other conditions such as asthma. There are limited studies looking at VCP post cardiac surgery, making it difficult to accurately assess and evaluate its implications, and translate findings into clinical practice. Follow-up studies targeting this cohort are warranted. 


\section{References:}

1. Liu Y, Chen S, Zühlke L, Black GC, Choy MK, Li N, Keavney BD (2019) Global birth prevalence of congenital heart defects 1970-2017: updated systematic review and meta-analysis of 260 studies. Int J Epidemiol 48(2):455-463. https://doi.org/10.1093/ije/dyz009

2. Bouma BJ, Mulder BJM (2017) Changing Landscape of Congenital Heart Disease. Circ Res 120(6):908-922. https://doi.org/10.1161/CIRCRESAHA.116.309302

3. van der Linde D, Konings EE, Slager MA, Witsenburg M, Helbing WA, Takkenberg JJ, Roos-Hesselink JW (2011) Birth prevalence of congenital heart disease worldwide: a systematic review and meta-analysis. J Am Coll Cardiol, 58(21):2241-2247. https://doi.org/10.1016/i.jacc.2011.08.025

4. Kim DS, Kim JH, Burt AA, Crosslin DR, Burnham N, McDonald-McGinn D, Zackai EH, Nicolson SC, Spray TL, Stanaway IB, Nickerson DA, Russell MW, Hakonarson H, Gaynor JW, Jarvik GP (2014) Patient genotypes impact survival after surgery for isolated congenital heart disease. Ann Thorac Surg 98(1):104-111. https://doi.org/10.1016/i.athoracsur.2014.03.017

5. Oster ME, Lee KA, Honein MA, Riehle-Colarusso T, Shin M, Correa A (2013) Temporal trends in survival among infants with critical congenital heart defects. Pediatrics 131(5):e1502e1508. https://doi.org/10.1542/peds.2012-3435

6. Daya H, Hosni A, Bejar-Solar I, Evans JNG, Bailey CM (2000) Pediatric Vocal Fold Paralysis. Arch Otolaryngol Head Neck Surg 126(1):21-25. https://doi.org/10.1001/archotol.126.1.21

7. Raut MS, Maheshwari A, Joshi R et al (2016) Vocal Cord Paralysis After Cardiac Surgery and Interventions: A Review of Possible Etiologies. J Cardiothorac Vasc Anesth 30(6):1661-1667. https://doi.org/10.1053/i.jvca.2016.08.002

8. Rodney JP, Thompson JL, Anderson MP, Burkhart HM (2019) Neonatal vocal fold motion impairment after complex aortic arch reconstruction: What should parents expect after diagnosis? Int J Pediatr Otorhinolaryngol 120:40-43. https://doi.org/10.1016/i.ijporl.2019.02.006

9. Henry BM, Hsieh WC, Sanna B, Vikse J, Taterra D, Tomaszewski KA (2019) Incidence, Risk Factors, and Comorbidities of Vocal Cord Paralysis After Surgical Closure of a Patent Ductus Arteriosus: A Metaanalysis. Pediatr Cardiol 40(1):116-125. https://doi.org/10.1007/s00246-018-1967-8

10. Alfares FA, Hynes CF, Ansari G, Chounoune R, Ramadan M, Shaughnessy C, Reilly BK, Zurakowski D, Jonas RA, Nath DS (2016) Outcomes of recurrent laryngeal nerve injury following congenital heart surgery: $A$ contemporary experience. J Saudi Heart Assoc 28(1):1-6. https://doi.org/10.1016/j.jsha.2015.05.002

11. Karas AF, Patki A, Ryan MA, Upchurch PA, Eapen RJ, Raynor EM (2019) Outcomes of Vocal Fold Immobility After Pediatric Cardiovascular Surgery. Otolaryngology - Open Journal 5(2):29-33. https://doi.org/10.17140/otloj-5-157

12. Shaath GA, Jijeh A, Alkurdi A, Ismail S, Elbarbary M, Kabbani MS (2012) Ultrasonography assessment of vocal cords mobility in children after cardiac surgery. J Saudi Heart Assoc 24(3):187-190. https://doi.org/10.1016/j.jsha.2012.02.009

13. Handler SD (1995) Direct laryngoscopy in children: rigid and flexible fiberoptic. Ear Nose Throat J 74(2):100-106.

14. Benjamin JR, Smith PB, Cotten CM, Jaggers J, Goldstein RF, Malcolm WF (2010) Long-term morbidities associated with vocal cord paralysis after surgical closure of a patent ductus arteriosus in extremely low birth weight infants. J Perinatol 30(6):408-413. https://doi.org/10.1038/jp.2009.124

15. Scott AR, Chong PST, Randolph GW, Hartnick CJ (2008) Intraoperative laryngeal electromyography in children with vocal fold immobility: A simplified technique. Int J Pediatr Otorhinolaryngol 72(1):31-40. https://doi.org/10.1016/i.ijporl.2007.09.011

16. Maturo SC, Braun N, Brown DJ, Chong PS, Kerschner JE, Hartnick CJ (2011) Intraoperative laryngeal electromyography in children with vocal fold immobility: results of a multicenter longitudinal study. Arch Otolaryngol Head Neck Surg 137(12):1251-1257. https://doi.org/10.1001/archoto.2011.184

17. Setlur J, Hartnick CJ (2012) Management of unilateral true vocal cord paralysis in children. Curr Opin Otolaryngol Head Neck Surg 20(6):497-501. https://doi.org/10.1097/MOO.0b013e3283590b56

18. Dewan K, Cephus C, Owczarzak V, Ocampo E (2012) Incidence and implication of vocal fold paresis following neonatal cardiac surgery. Laryngoscope 122(12):2781-2785. https://doi.org/10.1002/lary.23575

19. Lachanas VA, Exarchos S, Tsiouvaka S et al (2014) Does perioperative dexamethasone affect voice-related quality of life after thyroidectomy? Eur Arch Otorhinolaryngol 271:3073-3076. https://doi.org/10.1007/s00405-014-3168-2 
20. Misono S, Merati AL (2012) Evidence-Based Practice: Evaluation and Management of Unilateral Vocal Fold Paralysis. Otolaryngol Clin North Am. 45(5):1083-1108. https://doi.org/10.1016/i.otc.2012.06.011

21. Espinosa MC, Ongkasuwan J (2018) Recurrent laryngeal nerve reinnervation: Is this the standard of care for pediatric unilateral vocal cord paralysis? Curr Opin Otolaryngol Head Neck Surg 26(6):431-436. https://doi.org/10.1097/MO0.0000000000000499

22. Jabbour J, Martin T, Beste D, Robey T (2014) Pediatric vocal fold immobility: Natural history and the need for long-term follow-up. JAMA Otolaryngol Head Neck Surg 140(5):428-433. https://doi.org/10.1001/jamaoto.2014.81

23. Anthony B, Parker N, Patel R, Halum S (2020) Surgical Considerations for Laryngeal Reinnervation and Future Research Directions. Curr Otorhinolaryngol Rep, 8(3):224-229. https://doi.org/10.1007/s40136020-00294-7

24. Zur KB, Carroll LM (2015) Recurrent laryngeal nerve reinnervation in children: Acoustic and endoscopic characteristics pre-intervention and post-intervention. A comparison of treatment options. Laryngoscope 125:S1-S15. https://doi.org/10.1002/lary.25538

25. Meister KD, Johnson A, Sidell DR (2019) Injection Laryngoplasty for Children with Unilateral Vocal Fold Paralysis: Procedural Limitations and Swallow Outcomes. Otolaryngol Head Neck Surg 160(3):540-545. https://doi.org/10.1177/0194599818813002

26. Zeitels SM, Mauri M, Dailey SH (2003) Medialization laryngoplasty with Gore-Tex for voice restoration secondary to glottal incompetence: Indications and observations. Ann Oto Rhinol Laryn 112(2):180-184. https://doi.org/10.1177/000348940311200213

27. Butskiy O, Mistry B, Chadha NK (2015) Surgical interventions for pediatric unilateral vocal cord paralysis: A systematic review. JAMA Otolaryngol Head Neck Surg 141(7):654-660. https://doi.org/10.1001/jamaoto.2015.0680

28. Maragos NE (2001) Revision thyroplasty. Ann Oto Rhinol Laryn 110(12):1087-1092. https://doi.org/10.1177/000348940111001201

29. Isshiki N, Tanabe M, Sawada M (1978) Arytenoid Adduction for Unilateral Vocal Cord Paralysis. Arch Otolaryngol 104(10):555-558. https://doi.org/10.1001/archotol.1978.00790100009002

30. Hoffman MR, Surender K, Chapin WJ, Witt RE, Mcculloch TM, Jiang JJ (2011) Optimal Arytenoid Adduction Based on Quantitative Real-Time Voice Analysis. Laryngoscope 121:339-345. https://doi.org/10.1002/lary.21346

31. Marie JP, Hansen K, Brami P, Marronnier A, Bon-Mardion N (2020) Nonselective Reinnervation as a Primary or Salvage Treatment of Unilateral Vocal Fold Palsy. Laryngoscope 130(7):1756-1763. https://doi.org/10.1002/lary.28324

32. Paniello RC, Edgar JD, Kallogjeri D, Piccirillo JF (2011) Medialization versus reinnervation for unilateral vocal fold paralysis: A multicenter randomized clinical trial. Laryngoscope 121(10):2172-2179. https://doi.org/10.1002/lary.21754

33. Smith ME, Roy N, Houtz D (2012) Laryngeal reinnervation for paralytic dysphonia in children younger than 10 years. Arch Otolaryngol Head Neck Surg 138(12):1161-1166. https://doi.org/10.1001/jamaoto.2013.803

34. Ing C, DiMaggio C, Whitehouse A, Hegarty MK, Brady J, Von Ungern-Sternberg BS, Davidson A, Wood AJJ, Li G, Sun LS (2012) Long-term differences in language and cognitive function after childhood exposure to anaesthesia. Pediatrics 130(3):e476-e485. https://doi.org/10.1542/peds.2011-3822

35. Sipp JA, Kerschner JE, Braune N, Hartnick CJ (2007) Vocal Fold Medialization in Children. Arch Otolaryngol Head Neck Surg 133(8):767-771. https://doi.org/10.1001/archotol.133.8.767

36. Ongkasuwan J, Espinosa MCL, Hollas S, Devore D, Procter T, Bassett E, Schwabe A (2020) Predictors of voice outcome in pediatric non-selective laryngeal reinnervation. Laryngoscope 130(6):1525-1531. https://doi.org/10.1002/lary.28282

37. Li Y, Garrett G, Zealear D (2017) Current treatment options for bilateral vocal fold paralysis: A state-of-theart review. Clin Exp Otorhinolaryngol 10(3):203-212. https://doi.org/10.21053/ceo.2017.00199

38. Trozzi M, Meucci D, Salvati A, Tropiano ML, Bottero S, Hart C (2020) Surgical Options for Pediatric Bilateral Vocal Cord Palsy : State of the Art. Front Pediatr 8:1-9. https://doi.org/10.3389/fped.2020.538562

39. Westwood EL, Hutchins JV, Thevasagayam R (2019) Quality of life in paediatric tracheostomy patients and their caregivers - A cross-sectional study. Int J Pediatr Otorhinolaryngol 127:109606. https://doi.org/10.1016/i.ijporl.2019.109606

40. Young VN, Rosen CA (2011) Arytenoid and posterior vocal fold surgery for bilateral vocal fold immobility. Curr Opin Otolaryngol Head Neck Surg 19(6):422-427. https://doi.org/10.1097/MO0.0b013e32834c1f1c 
41. Crumley RL (1982) Experiments in laryngeal reinnervation. Laryngoscope 92(9):1-27) https://doi.org/10.1288/00005537-198209001-00001

42. Lee JW, Bon-Mardion N, Smith ME, Marie JP (2020) Bilateral Selective Laryngeal Reinnervation for Bilateral Vocal Fold Paralysis in Children. JAMA Otolaryngol Head Neck Surg 146(5):401-407. https://doi.org/10.1001/jamaoto.2019.4863

43. Zeitels SM, Hochman I, Hillman RE (1998) Adduction arytenopexy: a new procedure for paralytic dysphonia with implications for implant medialization. Ann Oto Rhinol Laryn Suppl 173:2-24. PMID: 9750545

44. Damrose EJ (2011). Suture laterofixation of the vocal fold for bilateral vocal fold immobility. Curr Opin Otolaryngol Head Neck Surg 19(6):416-421. https://doi.org/10.1097/MOO.0b013e32834c7d15

45. Mueller AH, Pototschnig C (2020). Recurrent Laryngeal Nerve Stimulator. Otolaryngol Clin North Am 53(1):145-156. https://doi.org/10.1016/i.otc.2019.09.009

46. Shiotani A, Saito K, Araki K, Moro K, Watabe K (2007) Gene therapy for laryngeal paralysis. Ann Otol Rhinol Laryngol 116(2):115-122. https://doi.org/10.1177/000348940711600207

47. Araki K, Suzuki H, Uno K, Tomifuji M, Shiotani A (2018) Gene Therapy for Recurrent Laryngeal Nerve Injury. Genes 9(7):p.316. https://doi.org/10.3390/genes9070316

48. Engeseth MS, Olsen NR, Maeland S, Halvorsen T, Goode A, Røksund OD (2018) Left vocal cord paralysis after patent ductus arteriosus ligation: A systematic review. Paediatr Respir Rev 27:74-85. https://doi.org/10.1016/j.prrv.2017.11.001

49. Pourmoghadam K, DeCampli W, Ruzmetov M, Kosko J, Kishawi S, O’Brien M, Cowden A, Piggott K, Fakioglu H (2017) Recurrent Laryngeal Nerve Injury and Swallowing Dysfunction in Neonatal Aortic Arch Repair. Ann Thorac Surg 104(5):1611-1618. https://doi.org/10.1016/i.athoracsur.2017.03.080

50. Fan L, Campbell D, Clarke D, Washington R, Fix E, White C (1989) Paralyzed left vocal cord associated with ligation of patent ductus arteriosus. J Thorac Cardiovasc Surg 98(4):611-613. https://doi.org/10.1016/S0022-5223(19)34364-8

51. Truong M, Messner A, Kerschner J, Scholes M, Wong-Dominguez J, Milczuk H, Yoon P (2007) Pediatric vocal fold paralysis after cardiac surgery: Rate of recovery and sequelae. Otolaryngol Head Neck Surg 137(5):780-784. https://doi.org/10.1016/j.otohns.2007.07.028

52. Zbar RIS, Chen AH, Behrendt DM, Bell EF, Smith RJH (1996) Incidence of Vocal Fold Paralysis in Infants undergoing ligation of patent ductus arteriosus. Ann Thorac Surg 61:814-6. https://doi.org/10.1016/00034975(95)01152-8

53. Nichols BG, Jabbour J, Hehir DA, Ghanayem NS, Beste D, Martin T, Woods R, Robey T (2014) Recovery of vocal fold immobility following isolated patent ductus arteriosus ligation. Int J Pediatr Otorhinolaryngol 78(8), 1316-1319. https://doi.org/10.1016/j.ijporl.2014.05.019

54. Skinner ML, Halstead LA, Rubinstein CS, Atz AM, Andrews D, Bradley SM (2005) Laryngopharyngeal dysfunction after the Norwood procedure. J Thorac Cardiovasc Surg 130(5):1293-1301. https://doi.org/10.1016/j.jtcvs.2005.07.013

55. Sachdeva R, Hussain E, Moss MM, Schmitz ML, Ray RM, Imamura M, Jaquiss RDB (2007) Vocal Cord Dysfunction and Feeding Difficulties after Pediatric Cardiovascular Surgery. J Pediatr 151(3):P312-315. https://doi.org/10.1016/j.jpeds.2007.03.014

56. Pereira K, Webb B, Blakely M, Cox C, Lally K (2006) Sequelae of recurrent laryngeal nerve injury after patent ductus arteriosus ligation. Int J Pediatr Otorhinolaryngol 70(9):1609-1612. https://doi.org/10.1016/i.ijporl.2006.05.001

57. Haraldstad K, Wahl A, Andenæs R et al (2019) A systematic review of quality of life research in medicine and health sciences. Qual Life Res 28(10):2641-2650. https://doi.org/10.1007/s11136-019-02214-9

58. Boseley ME, Cunningham MJ, Volk MS, Hartnick CJ (2006) Validation of the pediatric voice-related qualityof-life survey. Arch Otolaryngol Head Neck Surg 132(7):717-720. https://doi.org/10.1001/archotol.132.7.717

59. Walz PC, Hubbell MP, Elmaraghy CA (2014) Voice related quality of life in pediatric patients with a history of prematurity. Int J Pediatr Otorhinolaryngol 78(7):1010-1014. https://doi.org/10.1016/j.ijporl.2014.03.023

60. Khariwala S, Lee W, Koltai P (2005) Laryngotracheal Consequences of Pediatric Cardiac Surgery. Arch Otolaryngol Head Neck Surg 131(4):336-339. https://doi.org/10.1001/archotol.131.4.336

61. Richter AL, Ongkasuwan J, Ocampo EC (2016) Long-term follow-up of vocal fold movement impairment and feeding after neonatal cardiac surgery. Int J Pediatr Otorhinolaryngol 83:211-214. https://doi.org/10.1016/i.ijporl.2016.02.014 
62. Røksund OD, Clemm H, Heimdal JH, Aukland SM, Sandvik L, Markestad T, Halvorsen T (2010) Left vocal cord paralysis after extreme preterm birth, a new clinical scenario in adults. Pediatrics 126(6):e1569e1577. https://doi.org/10.1542/peds.2010-1129 
Tables:

\begin{tabular}{|c|c|c|c|}
\hline & Injection Laryngoplasty & Type 1 Thyroplasty & Non-selective recurrent laryngeal reinnervation \\
\hline Advantages & $\begin{array}{l}\text {-Immediate improvement } \\
\text {-Minimally invasive (endoscopic, } \\
\text { outpatient procedure) } \\
\text {-Minimal anaesthetic use }\end{array}$ & $\begin{array}{l}\text {-Immediate improvement } \\
\text {-Reversible - can remove implants. } \\
\text {-Less immunogenicity was reported for } \\
\text { materials than for IL. }\end{array}$ & $\begin{array}{l}\text {-Preserved laryngeal muscle bulk } \\
\text {-Does not preclude medialisation procedures } \\
\text {-Minimal foreign body and inflammatory reaction risk. } \\
\text {-Greater posterior glottic closure - no adjunct surgery needed. } \\
\text {-General anaesthesia - does not require patient cooperativity [35] }\end{array}$ \\
\hline $\begin{array}{l}\text { Disadvantag } \\
\text { es }\end{array}$ & $\begin{array}{l}\text {-Limited duration - ideal materials last } \\
\text { up to a few months. } \\
\text {-Irritation to native tissue and } \\
\text { histopathological changes. } \\
\text {-Reduces vocal fold elasticity - weaker } \\
\text { voice }\end{array}$ & $\begin{array}{l}\text {-Limited duration - requires revisions to } \\
\text { accommodate developing anatomy. } \\
\text {-Laryngeal muscle atrophy - progressive } \\
\text { denervation } \\
\text {-Pre-adolescent paediatric patients pose } \\
\text { procedural challenges } \\
\text {-Procedure is normally done awake or under } \\
\text { light sedation and requires cooperativity. } \\
\text {-General anaesthesia may be required for } \\
\text { which concerns exist about neurocognitive } \\
\text { effects with prolonged procedures [34] } \\
\text { Involving children under } 3 \text { years old [37]. } \\
\text {-Requires adjunct arytenoid adduction } \\
\text { because it does not correct persistent } \\
\text { posterior phonatory gaps }\end{array}$ & $\begin{array}{l}\text {-Average time of } 4.5 \text { months to improve voice quality [33] } \\
\text { observation period in older children is } \sim 12 \text { months. } \\
\text {-General anaesthesia - neurocognitive impairment [41] risk if under } \\
3 \text { years old [37] }\end{array}$ \\
\hline
\end{tabular}

Table 1: Comparison of the positives and drawbacks of injection laryngoplasty, Type 1 thyroplasty, and NSLR adapted from Espinosa et al [21] unless indicated otherwise. 


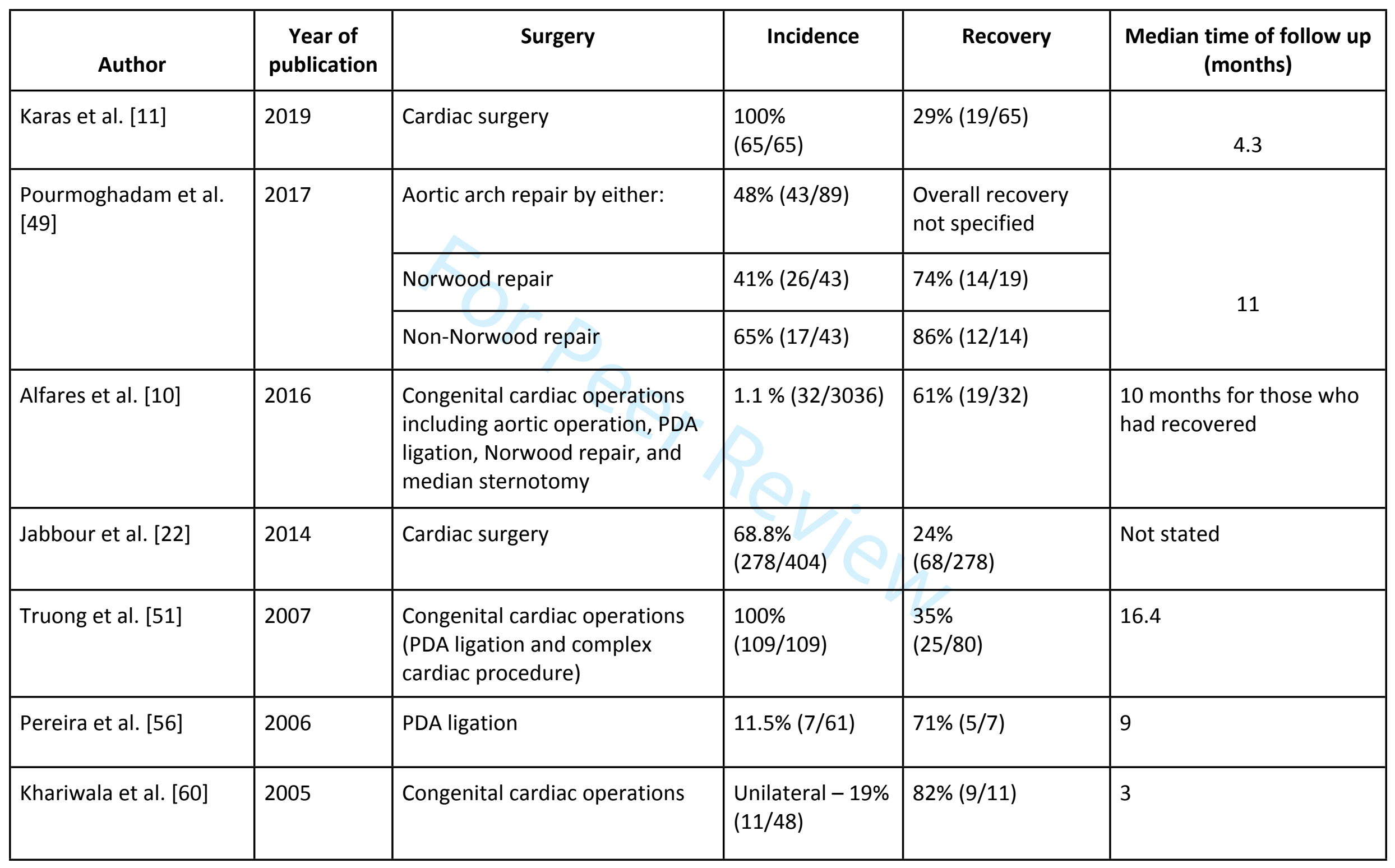




\begin{tabular}{|l|l|l|l|l|l|}
\hline & & & $\begin{array}{l}\text { Bilateral }-6 \% \\
(3 / 48)\end{array}$ & Not stated & Not stated \\
\hline Zbar et al. [52] & 1996 & PDA ligation & $8.8 \%, 6 / 68$ & $0 \%$ & 6 \\
\hline Fan et al. [50] & 1989 & PDA ligation & $4.2 \%(7 / 167)$ & $0 \%$ & Not stated \\
\hline
\end{tabular}

Table 2: A summary on the incidence, recovery and follow up period for VCP following cardiac surgery $[10,11,22,49,50,51,52,56,60]$ 
Figure 1. classification of risks of each surgical procedure in relation to developing vocal cord palsy

$311 \times 143 \mathrm{~mm}(72 \times 72$ DPI $)$

Figure 1: A flow chart summarising the recommended otolaryngology follow-up algorithm adapted from Jabbour et al. [22] 


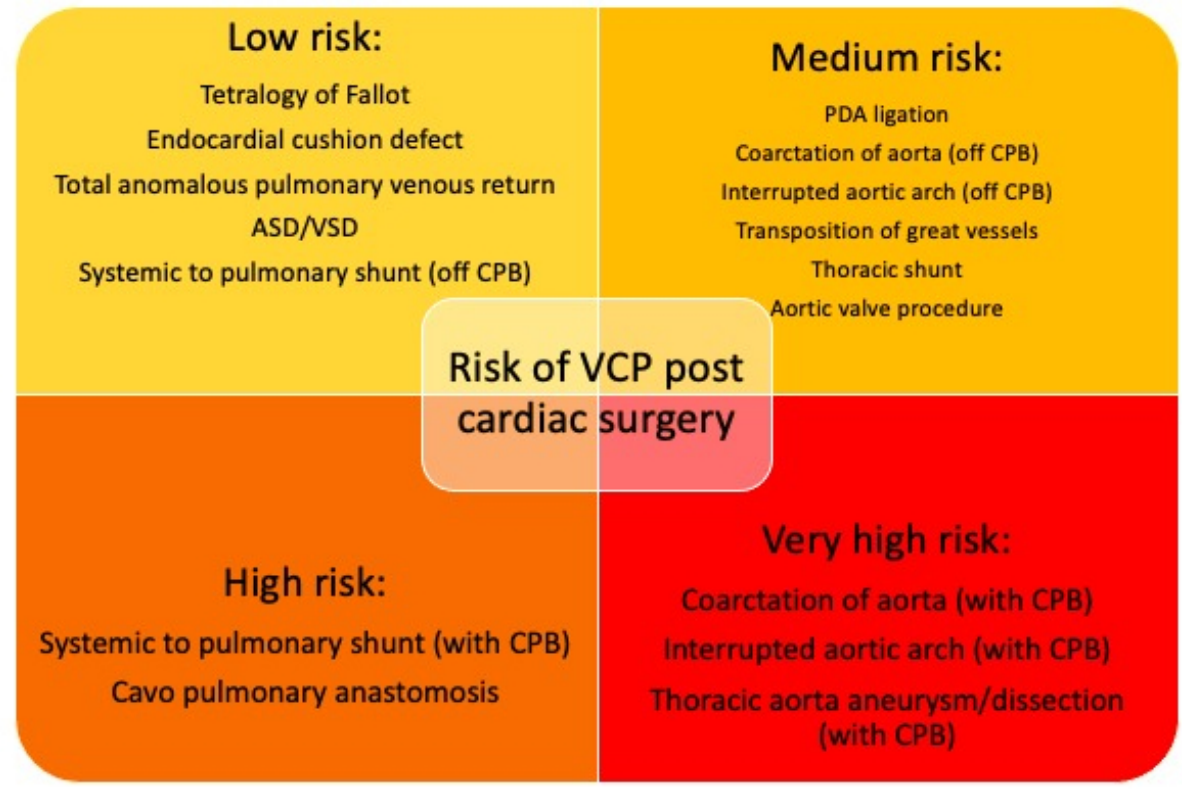

figure 2

$224 \times 155 \mathrm{~mm}(72 \times 72$ DPI $)$ 